Document downloaded from:

http://hdl.handle.net/10251/46854

This paper must be cited as:

García García, A.; Llopis Castelló, D.; Camacho Torregrosa, FJ.; Pérez Zuriaga, AM. (2013). New consistency index based on inertial operating speed. Transportation Research Record. (2391):105-112. doi:10.3141/2391-10.

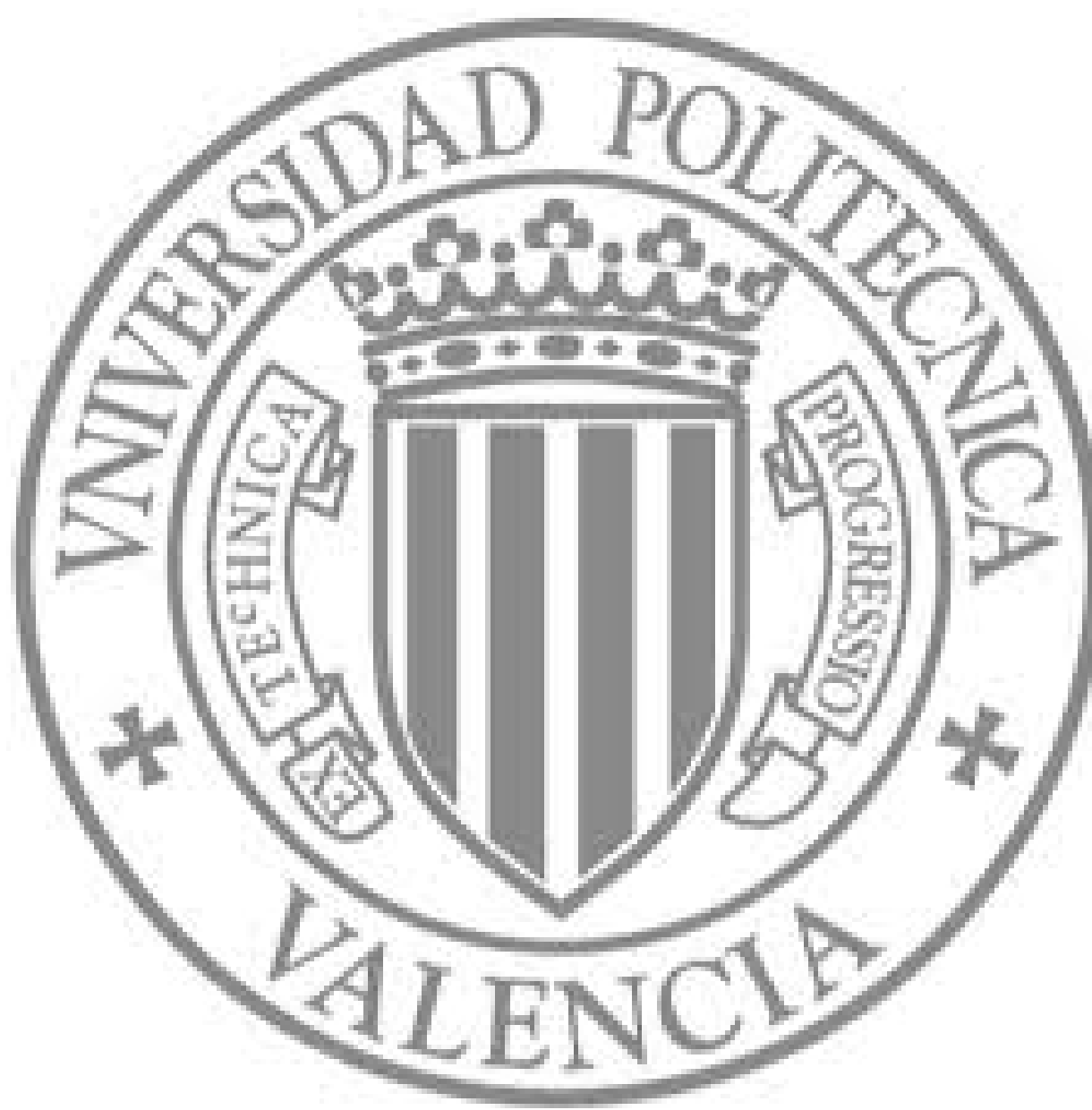

The final publication is available at

http://dx.doi.org/10.3141/2391-10

Copyright National Academy of Sciences 


\title{
NEW CONSISTENCY INDEX BASED ON INERTIAL OPERATING SPEED
}

Corresponding Author:

\author{
Alfredo García \\ Professor \\ Highway Engineering Research Group, Universitat Politècnica de València \\ Camino de Vera, s/n. 46022 - Valencia. Spain \\ Tel: (34) 963877374 \\ Fax: (34) 963877379 \\ E-mail: agarciag@tra.upv.es
}

Other Authors:

\section{David Llopis-Castelló}

Ph.D. Candidate

Highway Engineering Research Group, Universitat Politècnica de València Camino de Vera, s/n. 46022 - Valencia. Spain

Tel: (34) 963877374

Fax: (34) 963877379

E-mail: dallocas@cam.upv.es

\section{Francisco Javier Camacho-Torregrosa}

Ph.D. Candidate

Highway Engineering Research Group, Universitat Politècnica de València

Camino de Vera, s/n. 46022 - Valencia. Spain

Tel: (34) 963877374

Fax: (34) 963877379

E-mail: fracator@cam.upv.es

\section{Ana María Pérez-Zuriaga}

$\mathrm{Ph} . \mathrm{D}$.

Highway Engineering Research Group, Universitat Politècnica de València

Camino de Vera, s/n. 46022 - Valencia. Spain

Tel: (34) 963877374

Fax: (34) 963877379

E-mail: anpezu@tra.upv.es

Submission date: March $7^{\text {th }}, 2013$

$\begin{array}{llr}\text { Word count: } & \text { Abstract: } & 250 \\ & \text { Manuscript: } & 3960 \\ & \text { Figures: 9 x 250 = } & 2250 \\ & \text { Tables: 2 x 250 = } & 500 \\ & \text { TOTAL: } & \mathbf{6 9 6 0}\end{array}$

Key words: Road safety, design consistency, operating speed, geometric design, inertial operating speed, inertial consistency index. 


\begin{abstract}
Road crashes occurrence depends on several factors, being the design consistency one of the most important. It refers to the conformance of highway geometry to drivers' expectations.

A new consistency model for evaluating the performance of tangent-to-curve transitions on two-lane rural roads is presented. It is based on the Inertial Consistency Index (ICI), defined for each transition. It is calculated at the beginning point of the curve, as the difference between the average operating speed of the previous $1 \mathrm{~km}$ road segment (inertial operating speed) and the operating speed at this point.

88 road segments, which included 1,686 tangent-to-curve transitions, were studied in order to calibrate ICI and its thresholds. The relationship between those results and the crash rate associated to each transition has been analyzed. It has been pointed out that the higher the ICI is, the higher the crash rate is, thus increasing the probability of accidents to take place. Similar results were obtained from the study of the relationship between ICI and the weighted average crash rate of the corresponding group of transitions.

A graphical and statistical analysis established that road consistency may be considered good when ICI is lower than $10 \mathrm{~km} / \mathrm{h}$; poor when ICI is higher than $20 \mathrm{~km} / \mathrm{h}$; and fair otherwise.

A validation process has been carried out considering 20 road segments. The obtained ICI values were highly correlated to the number of crashes which had occurred at the analyzed transitions. Hence, the Inertial Consistency Index (ICI) and its consistency thresholds resulted in a new approach for consistency evaluation.
\end{abstract}




\section{INTRODUCTION}

Road crashes have three general categories of contributing factors: human factor, vehicle factor and road infrastructure factor. Previous research (1) pointed out that the infrastructure factor is responsible for over 30\% of road crashes. In fact, collisions tend to concentrate on certain road segments, highlighting that road characteristics play a major role in some accidents.

The influence of road geometric characteristics increases when the geometric design consistency level is low. Road geometric consistency may be defined as how drivers' expectations and road behavior fit. An inconsistent road design surprises drivers, leading to anomalous behavior and possible collisions.

Most of the related research and developed design consistency models focus on four main areas: operating speed and its variations, vehicle stability, alignment indexes and driver workload (2, 3 ). Among them, the most worldwide used criteria for road design consistency evaluation are based on the operating speed evaluation (4). Operating speed is often defined as the $85^{\text {th }}$ percentile speed $\left(\mathrm{V}_{85}\right)$ of the distribution of speeds selected by drivers in free-flow conditions. This specific measure of speed can be used in consistency evaluation by examining differences between design speed $\left(V_{d}\right)$ and $\mathrm{V}_{85}$ or examining the differences in $\mathrm{V}_{85}$ between successive road elements, especially between horizontal curves and previous tangents. In fact, tangent-to-curve transitions are considered the most critical locations since it is estimated that more than $50 \%$ of the total fatalities on rural highways take place on curved sections (5).

Leisch and Leisch (6) recommended a revised design speed concept that included guidelines on both operating speed reductions and differentials between design and operating speed. In the same way, Kanellaidis et al. (7) suggested that a good design can be achieved when the difference between $\mathrm{V}_{85}$ on the tangent and on the following curve does not exceed $10 \mathrm{~km} / \mathrm{h}$.

However, the most commonly used method to evaluate road consistency was developed by Lamm et al. (8), based on mean accident rates observed at several alignment configurations. They presented two design consistency criteria related to operating speed, which included the difference between design and operating speed (criterion I) and the difference between operating speeds on successive elements (criterion II).

The difference between operating speed and design speed $\left(\left|V_{85}-V_{d}\right|\right)$ allows the identification of road alignment elements whose design does not fit the general road alignment. It is a good indicator of the consistency on one single element.

The operating speed reduction between two successive elements $\left(\Delta V_{85}\right)$ indicates the surprises experienced by drivers, making them to reduce their speed, when traveling from one element to the next.

Table 1 summarized the consistency thresholds for criteria I and II. Those thresholds are an approach to the thresholds that determine the need for redesign. However, other authors (9) suggested continuous functions instead of consistency thresholds, as a better tool for designers.

The consistency criteria previously presented allow design consistency evaluation on a single road element (the horizontal curve) or at tangent-to-curve transitions. They are usually called local consistency models.

Local consistency models try to identify road inconsistencies by considering that drivers' expectations are failed when operating speed is much higher than design speed; or by assuming that drivers are surprised when the operating speed in a road element is much lower than the previous one.

Hence, drivers' expectations are assumed to be characterized as the design speed of the whole road segment or as the operating speed in the previous element. While in the first case the road segment immediately preceding the inconsistency is not taken into account; in the second one only the previous element is considered.

However, there is no previous research which determines the road segment length necessary for producing ad hoc expectations, which may be compared to road design geometry.

Other studies, such as the one carried out by Polus and Mattar-Habib (10), Cafiso et al. (11) and Camacho-Torregrosa et al. (12), are based on continuous speed profiles. They studied the global speed variation along a road segment, as a function of several indexes, and determined a single consistency value for the whole road segment. Moreover, their design consistency index is a continuous function instead of being based on ranges. 
Those global consistency models are less used than local ones due to the difficulty of continuous operating speed estimation.

Finally, it is important to highlight that each consistency model was calibrated at a specific geographic environment and that drivers' behavior may change from one region to other. Therefore, the extrapolation of those models or thresholds should be carefully carried out. In fact, further test for the applicability of Lamm's criteria revealed that a $20 \mathrm{~km} / \mathrm{h}$ limit for poor design is applicable to Korea (13), but a different limit was recommended for Italy (14).

Taking into account the previous considerations, this paper presents a new model for consistency evaluation of two-lane rural roads. It is based on the comparison of ad hoc drivers' expectations and road design geometry, since it is the definition of road consistency.

\section{OBJECTIVES AND HYPOTHESES}

The main objective of this study is the development of a new index for two-lane rural road design consistency evaluation that allows including drivers' expectations within the analysis.

This development is based on the hypothesis that drivers' expectations at one point station can be estimated as the average operating speed at the previous road segment. This speed parameter is called inertial operating speed $\left(\mathrm{V}_{85}\right.$ inertial $)$. According to this hypothesis, the difference between inertial operating speed and operating speed shows the discordance between drivers' expectations and road alignment.

\section{DATA DESCRIPTION}

Tangent-to-curve transitions are the most conflictive points of a road alignment. In fact, Lamm et al. (5) estimated that more than $50 \%$ of fatal accidents occur on rural roads on those locations. This is why the proposed consistency model is focused on those transitions.

For its development, 88 two-lane rural road segments from the Valencian region (Spain) were evaluated, identifying 1,686 tangent-to-curve transitions. The length of the road segments ranged from $2.0 \mathrm{~km}$ to $15.5 \mathrm{~km}$, being their longitudinal grades between $-3 \%$ and $3 \%$. None of the selected road segments presented important intersections that could significantly vary traffic volumes, operating speeds and number of crashes.

\section{Traffic volume}

Traffic volume data was downloaded from the official website of the Valencian local road administration. It consisted on AADT data for the last 15 years, but only data from 2001 to 2010 were used in order to avoid considering of data belonging to road segments that were redesigned or improved during that period of time. The highest traffic volume considered was 25,015 vpd, while the road segment with the lowest AADT presented only $363 \mathrm{vpd}$.

\section{Crash data}

Crash data were also provided by the Valencian local road administration. It consisted on a list of all reported crashes during those years, characterized by point station, date and time, lighting conditions, crash severity, type of vehicle, characteristics of the driver, external factors, causes and other conditions. Considering all data, a filtering process was performed, discarding all property damage only accidents in order to prevent bias due to underreporting problems. Accidents caused by external factors, such as previous illness of the driver or animals crossing the road, were also removed from the analysis.

Thanks to data characterization, crash locations and driving directions were identified. However, the accuracy of crash locations was one hectometer, so relating the crashes to their corresponding tangent-to-curve transition could not be directly performed. It was considered that each accident could have been produced within a range $[-50 \mathrm{~m},+50 \mathrm{~m}]$ from its reported location. An accident is considered to be transition-related if its actual location yields within the curve or 100 beyond, due to kinematic effects. Considering the uncertainty of the accident location, an accident was considered to be transition-related if its reported location is somewhere between $50 \mathrm{~m}$ before and $150 \mathrm{~m}$ after the corresponding curve. 


\section{Continuous operating speed profiles}

The operating speed profiles were based on operating speed models developed by Pérez-Zuriaga et al. (15). The operating speed model for curves uses the radius as explanatory variable (Eq. 1 and 2).

$$
\begin{aligned}
& V_{85 C}=97.4254-\frac{3310.94}{R} ; \quad 400 m<R \leq 950 m \\
& V_{85 C}=102.048-\frac{3990.26}{R} ; \quad 70 m<R \leq 400 m
\end{aligned}
$$

Where:

$V_{85 C}$ : operating speed on curve $(\mathrm{km} / \mathrm{h})$

$R$ : horizontal curve radius (m)

This model does not consider radius lower than $70 \mathrm{~m}$. However, it was not necessary since none of the road segments presented any curve with radius lower than $70 \mathrm{~m}$.

The developed model for estimating operating speed on tangents considers the length of the tangent and the estimated operating speed of the preceding curve (Eq. 3).

$V_{85 T}=V_{85 C}+\left(1-e^{-\lambda \cdot L}\right) \cdot\left(V_{d e s}-V_{85 C}\right)$

Where:

$V_{85 T}$ : operating speed on tangent $(\mathrm{km} / \mathrm{h})$

$V_{85 C}$ : operating speed on previous curve $(\mathrm{km} / \mathrm{h})$

$V_{\text {des }}:$ desired speed $(110 \mathrm{~km} / \mathrm{h})$

$L$ : tangent length $(\mathrm{m})$

$\lambda=0.00135+(R-100) \cdot 7.00625 \cdot 10^{-6}$

$R$ : horizontal curve radius $(\mathrm{m})$

Considering these models, the operating speed profiles were built, both in forward and backward directions, for all road segments. Some construction rules and deceleration and acceleration rates estimated by Equation 4 and 5 had also to be considered in their construction. Those models were calibrated by Pérez-Zuriaga et al. (15) and Camacho-Torregrosa et al. (12), respectively.

$d_{85}=0.313+\frac{114.436}{R}$

$a_{85}=0.41706+\frac{65.93588}{R}$

Where:

$d_{85}:$ deceleration rate $\left(\mathrm{m} / \mathrm{s}^{2}\right)$

$a_{85}:$ acceleration rate $\left(\mathrm{m} / \mathrm{s}^{2}\right)$

$R$ : horizontal curve radius $(\mathrm{m})$

\section{DEVELOPMENT}

Road safety is highly correlated with road design consistency, so every design consistency model should be calibrated considering its relationship to crashes.

The representative index of the proposed model is the difference between inertial operating speed $\left(\mathrm{V}_{85}\right.$ inertial $)$, as an estimation of drivers' expectations, and operating speed $\left(\mathrm{V}_{85}\right)$, as an estimation of road geometry performance. The new index is called inertial consistency index (ICI).

$\mathrm{V}_{85}$ inertial was defined as the average operating speed of the previous road segment for each point of the road. It was first necessary to identify which length should be used for constructing this index. This was carried out by means of a sensitivity analysis. The aim of this study was to determine 
which road segment length better reflects drivers' behavior. Several road segment lengths were evaluated. The use of road segment lengths lower than 1,000 m led to an inertial operating speed profile slightly smoother than the corresponding operating speed profile, without significant contributions compared to the operating speed profile. At the other extreme, road segment lengths higher than $1,000 \mathrm{~m}$ resulted in a too smooth profile, hiding the significant speed variations.

After this evaluation, it was concluded that the most suitable road segment length for this kind of study was $1,000 \mathrm{~m}$. Hence, $\mathrm{V}_{85}$ inertial was finally defined as the $1,000 \mathrm{~m}$ moving average value of the operating speed. Figure 1 shows an example of inertial operating speed profile, both in forward and backward directions.

The next step was to calibrate the relationship between the new consistency index and the corresponding crash rate. The consistency index was determined at the beginning of the curve of each tangent-to-curve transition. In order to establish consistency thresholds, the ICI was also grouped into several intervals and the average crash rates were obtained for all of them.

\section{Crash rate vs ICI}

The crash rate of each tangent-to-curve transition was calculated as the quotient between the number of crashes and the total traffic volume in each transition. ICI was also determined for each tangent-tocurve transition. The relationship between those variables is shown in Figure 2.

Figure 2 shows a clear relationship between crash rate and ICI. The higher the ICI is, the higher the crash rate is. However, it was not possible to obtain general conclusions from this graph because of the large amount of data without crashes that may bias results and conclusions.

\section{Weighted average crash rate vs ICI}

The second analysis was based on considering the relationship between the ICI and the weighted average crash rate (WACR). Two kinds of graphs were used in this part of the analysis. The first one is shown in Figure 3. ICI values were put into groups of $5 \mathrm{~km} / \mathrm{h}$. For each group, the weighted average crash rate was calculated as the quotient between the total number of crashes with a certain interval of ICI, and the total traffic volume of them.

Grey columns reflect the calculated WACR considering all the curves and the black ones correspond to the WACR, previously removing the transitions with no accidents. This data treatment was carried out because of the high amount of data without crashes that could have a serious influence on the results of the analysis.

From the statistical point of view, crashes are rare, random and discrete events. This is why they should be adjusted to a Poisson or a negative binomial distribution. However, this one does not correctly fit to data when there is a high amount of zeros. In this case, zero-crash tangent-to-curve transitions may be associated to a safe transition or to the randomness of the crash phenomenon. There are some methodologies, such as Bayesian analyses, that differentiate between both data groups, improving the results of the analysis.

Nevertheless, this analysis is only useful when a large data sample is available. In this case, data set was not enough to perform this calculation, so a different methodology was carried out. Two different calculations, with and without consideration of blank transitions, were carried out. The real result was assumed to be between both solutions.

A similar graph was plotted setting ICI into groups of $10 \mathrm{~km} / \mathrm{h}$ intervals (Figure 4). Both graphs showed that WACR increases as ICI does.

Since there is a high proportion of curves without crashes (blank transitions), it was studied, for each interval, its percentage compared to the total number of transitions (Figures 5 and 6).

Figures 5 and 6 show a decreasing trend of the percentage of blank transitions with the ICI. This result points out that the proportion of curves with accidents increases as the difference between inertial operating speed and operating speed does. According to that, it can be concluded that the ICI presents a strong relationship with road safety. Therefore, the increase of the ICI is related to a higher probability of crash occurrence in the tangent-to-curve transition. 


\section{Thresholds analysis}

Once the relationship between the ICI and road safety was demonstrated, it was necessary to establish the intervals of values of this index where the influence of the road design consistency index on road safety can be considered the same.

So, weighted average crash rate represented in Figure 3 clearly shows a general increasing trend, divided in two minor trends. The first one ranges from $-2.5 \mathrm{~km} / \mathrm{h}$ to $12.5 \mathrm{~km} / \mathrm{h}$, while the second one is from $12.5 \mathrm{~km} / \mathrm{h}$ to $27.5 \mathrm{~km} / \mathrm{h}$.

The differences between trends are shown clearer in Figure 4. As can be seen, the trend almost remains horizontal from $-10 \mathrm{~km} / \mathrm{h}$ to $10 \mathrm{~km} / \mathrm{h}$ and dramatically increases up in the $[10 ; 20]$ $\mathrm{km} / \mathrm{h}$ interval. The $[20 ; 30] \mathrm{km} / \mathrm{h}$ interval shows even a higher increase.

A statistical analysis was carried out in order to confirm those thresholds. This process was carried out by means of least significant difference (LSD) intervals (Figure 7), comparing different ICI intervals. It can be assumed that two ICI ranges belong to different populations (i.e., different tangent-to-curve behavior) when their intervals do not overlap.

This analysis pointed out that there are statistical significant differences with a $95 \%$ confidence level between tangent-to-curve transitions with ICI between $[0 ; 10] \mathrm{km} / \mathrm{h}$ and those with ICI between $[10 ; 20] \mathrm{km} / \mathrm{h}$, and between $[0 ; 10] \mathrm{km} / \mathrm{h}$ and $[20 ; 30] \mathrm{km} / \mathrm{h}$ as well. Both results were obtained taking into account all the curves, as well as not considering blank curves.

However, the tangent-to-curve transitions where ICI ranges from 10 to $20 \mathrm{~km} / \mathrm{h}$ and from 20 to $30 \mathrm{~km} / \mathrm{h}$ seem to belong to the same population. This result is due to small data sample for this interval (15 not-blank tangent-to-curve transitions). This also causes higher crash rate dispersion. It is suggested to increase this sample for further research.

\section{PROPOSED GEOMETRIC DESIGN CONSISTENCY MODEL}

As stated previously, the Inertial Consistency Index (ICI) is related to safety and may be used for analyzing safety at tangent-to-curve transitions. Threshold values are defined in Table 2, as obtained before.

As demonstrated above, a higher difference between inertial operating speed (i.e. drivers' expectations) and operating speed (i.e. road geometric design) results in a lower consistency and therefore, a higher crash probability.

\section{VALIDATION}

The validation of the proposed model for geometric design consistency evaluation was carried out applying it to other 20 two-lane rural road segments, including 370 tangent-to-curve transitions. Empirical operating speed profiles were used for validation. The corresponding empirical operating speed profiles were obtained by the application of the data collection methodology developed by Pérez-Zuriaga et al. (15). This methodology consisted on asking drivers to install a GPS device, which has strong magnetic points, between two checkpoints belonging to each road segment. Drivers were encouraged to drive as they usually do. This method allowed collection of continuous speed data along a road segment from a great number of individual drivers. Additional tests were performed in order to ensure that drivers were not biased by the presence of the checkpoints or the device (15).

As was expected, tangent-to-curve transitions identified as inconsistent by the ICI model presented a higher crash concentration than the rest within the same road segment. Figure 8 shows the road consistency evaluation and crash locations for one road segment.

In order to improve the validation analysis, a graph comparing ICI with weighted average crash rate (WACR) was performed (Figure 9), including all tangent-to-curve transitions located at the 20 road segments used in this process. Grey columns correspond to WACR considering all the transitions and the black ones correspond to WACR considering only transitions with accidents.

Figure 9 shows an increasing trend of the weighted average crash rate with the difference between the inertial operating speed and the operating speed. In fact, the WACR differences between the intervals of ICI values are even higher than in the model calibration process. The inflection points clearly correspond to the thresholds identified for the consistency model. 


\section{CONCLUSIONS}

Road safety and, specially, fatal crashes are one of the most important problems in our society. The infrastructure factor is found in $30 \%$ of road crashes occurring on two-lane rural roads. In fact, collisions tend to concentrate on certain road segments, road characteristics playing a major role at some accidents. Besides, tangent-to-curve transitions are considered the most conflictive points as more than $50 \%$ of crashes are located on those sections.

In order to improve road geometric design and road safety evaluation, this paper presents a new design consistency model for evaluating the quality of tangent-to-curve transitions on two-lane rural roads. The proposed model is based on the hypothesis that design consistency may be defined as the difference between drivers' expectations and road alignment behavior.

The road alignment behavior on one station may be estimated by means of the operating speed at that point. Drivers' expectations may be estimated by the inertial operating speed on the same point, defined as the average operating speed of the previous $1 \mathrm{~km}$ road segment. The difference between both parameters, called Inertial Consistency Index (ICI), results in a new approach for road consistency evaluation.

The ICI and the associated consistency thresholds were developed studying the operating speed profiles of 44 two-lane rural road segments considering both driving directions, which included 1,686 tangent-to-curve transitions. $V_{85}$ inertial $-V_{85}$ was calculated at the beginning point of the curve of each transition. The relationship between those results and the crash rate associated to each transition from 2001 to 2010 was examined. This relationship pointed out that higher crash rates corresponded to higher ICI values. Therefore, a high ICI is linked to a higher crash probability.

A graphical and a statistical analysis were carried out in order to establish the thresholds of the consistency model. According to these analyses, road alignment consistency at every location may be considered good when ICI is lower than $10 \mathrm{~km} / \mathrm{h}$; fair when it is between $10 \mathrm{~km} / \mathrm{h}$ and $20 \mathrm{~km} / \mathrm{h}$; and poor when ICI is higher than $20 \mathrm{~km} / \mathrm{h}$.

The proposed consistency model was validated with its application to the empirical operating speed profiles of 20 road segments, which included 370 tangent-to-curve transitions. The obtained ICI values were correlated to the number of crashes occurred at the studied transitions. The validation process pointed out that the transitions with higher ICI value presented more collisions.

\section{ACKNOWLEDGEMENTS}

Authors would like to thank Center for Studies and Experimentation of Public Works (CEDEX) of the Spanish Ministry of Public Works that partially subsidizes the data collection for obtaining the empirical operating speed profiles used in the validation process.

Also thank to the General Directorate of Public Works of the Infrastructure and Transportation Department of Valencian Government; Valencian Province Council; and to the General Directorate of Traffic of the Ministry of the Interior of the Government of Spain, for their cooperation in data gathering.

\section{REFERENCES}

1. Treat, J.R, Tumbas, N.S., McDonald, S.T., Shinar, D., Hume, R.D., Mayer, R.E., Stansifer, R.L. and Castellan, N.J. Tri-level study of the causes of traffic accidents: Final report - Executive summary. Publication DOT-HS-034-3-535-79-TAC(S). Bloommington. Institute for Research in Public Safety, 1979.

2. Ng, J. C. W. and Sayed, T. Effect of Geometric Design Consistency on Road Safety. In Canadian Journal of Civil Engineering, Vol. 31, No. 2, National Research Council of Canada, Canada, 2004, pp. 218-227.

3. Awata, M. and Hassan, Y. Towards Establishing an Overall Safety-Based Geometric Design Consistency Measure. Presented at 4th Transportation Specialty Conference of the Canadian Society for Civil Engineering, 2002.

4. Gibreel, G. M., Easa, S.M., Hassan, Y. and El-Dimeery, I.A. State of the Art of Highway Geometric Design Consistency. In Journal of Transportation Engineering, Vol. 125, No. 4, American Society of Civil Engineers (ASCE), U.S.A., 1999, pp. 305-313. 
5. Lamm, R., Choueiri, E. M. and Mailaender, T. Traffic safety on two continents-a ten year analysis of human and vehicular involvements. Proceedings of the Strategic Highway Research Program (SHRP) and Traffic Safety on Two Continents, 1992, pp. 18-20.

6. Leisch, J. E., and Leisch, J. P. New Concepts in Design-Speed Application. In Transportation Research Record: Journal of the Transportation Research Board, No. 631, Transportation Research Board of the National Academies, Washington, D.C., 1977, pp. 4-14.

7. Kanellaidis, G., Golias, J., and Efstathiadis, S. Driver's speed behaviour on rural road curves. In Traffic Engineering and Control, Vol. 31(7/8), Hemming Group, Greece, 1990, pp. 414-415.

8. Lamm, R., Psarianos, B. and Mailaender, T. Highway design and traffic safety engineering handbook. McGraw-Hill Companies, Inc., 1999.

9. Hassan, Y. Highway Design Consistency: Refining the State of Knowledge and Practice. In Transportation Research Record: Journal of the Transportation Research Board, Vol. 1881, Transportation Research Board of the National Academies, Washington, D.C., 2004, pp. 63-71.

10. Polus, A. and Mattar-Habib, C. New Consistency Model for Rural Highways and its Relationship to Safety. In Journal of Transportation Engineering, Vol. 130, No. 3, American Society of Civil Engineers (ASCE), U.S.A., 2004, pp.286-293.

11. Cafiso, S., Di Graziano, A., Di Silvestro, G., La Cava, G. and Persaud, B. Development of comprehensive accident models for two-lane rural highways using exposure, geometry, consistency and context variables. In Accident Analysis and Prevention, Vol. 42, No. 4, Elsevier, 2010, pp. 1072-1079.

12. Camacho-Torregrosa, F. J., Pérez-Zuriaga, A. M., Campoy-Ungría, J.M, and García García, A. New Geometric Design Consistency Model Based on Operating Speed Profiles for Road Safety Evaluation. In Accident, Analysis and Prevention, accepted DOI: 10.1016/j.aap.2012.10.001, Elsevier Limited, 2012.

13. Lee, S., D. Lee, and J. Choi. Validation of the 10 MPH Rule in Highway Design Consistency Procedure. Proceedings of 2nd International Symposium on Highway Geometric Design, Mainz, Germany, 2000, pp. 364-376.

14. Cafiso, S. Experimental Survey of Safety Condition on Road Stretches with Alignment Inconsistencies. Proceedings of 2nd International Symposium on Highway Geometric Design, Mainz, Germany, 2000, pp. 377-387.

15. Pérez-Zuriaga, A.M., García, A., Camacho-Torregrosa, F.J. and D’Attoma, P. Modeling operating speed and deceleration on two-lane rural roads with global positioning system data. Transportation Research Record: Journal of the Transportation Research Board, Vol. 2171, Transportation Research Board of the National Academies, Washington, D.C., 2010, pp.11-20. 


\section{LIST OF TABLES AND FIGURES}

TABLE 1 Thresholds for design consistency quality determination. Lamm's criteria I \& II.

TABLE 2 Thresholds design consistency evaluation. Proposed model.

5

6 FIGURE 1 Example of inertial operating speed profile

7 FIGURE 2 Crash rate vs ICI

8 FIGURE 3 Weighted average crash rate vs ICI $(5 \mathrm{~km} / \mathrm{h}$ intervals)

9 FIGURE 4 Weighted average crash rate vs ICI $(10 \mathrm{~km} / \mathrm{h}$ intervals $)$

10 FIGURE 5 Percentage of blank transitions vs ICI $(5 \mathrm{~km} / \mathrm{h}$ intervals $)$

11 FIGURE 6 Percentage of blank transitions vs ICI $(10 \mathrm{~km} / \mathrm{h}$ intervals $)$

12 FIGURE 7 LSD intervals (95.0 percentage) for model thresholds determination

13 FIGURE 8 Validation road segment example. Inconsistencies identification and crashes location

14 FIGURE 9 Weighted average crash rate vs ICI $(10 \mathrm{~km} / \mathrm{h}$ intervals) for validation road segments 
1 TABLE 1 Thresholds for design consistency quality determination. Lamm's criteria I \& II.

\begin{tabular}{|c|c|c|}
\hline Consistency rating & Criterion I $(\mathrm{km} / \mathrm{h})$ & Criterion II $(\mathrm{km} / \mathrm{h})$ \\
\hline Good & $\left|V_{85}-V_{d}\right| \leq 10$ & $\left|V_{85 i}-V_{85 i+1}\right| \leq 10$ \\
\hline Fair & $10<\left|V_{85}-V_{d}\right| \leq 20$ & $10<\left|V_{85 i}-V_{85 i+1}\right| \leq 20$ \\
\hline Poor & $\left|V_{85}-V_{d}\right|>20$ & $\left|V_{85 i}-V_{85 i+1}\right|>20$ \\
\hline
\end{tabular}

2 
1 TABLE 2 Thresholds design consistency evaluation. Proposed model.

\begin{tabular}{|c|c|c|}
\hline Good & Fair & Poor \\
\hline$V_{85 \text { inertial }}-V_{85} \leq 10 \mathrm{~km} / \mathrm{h}$ & $10<V_{85 \text { inertial }}-V_{85} \leq 20 \mathrm{~km} / \mathrm{h}$ & $V_{85 \text { inertial }}-V_{85}>20 \mathrm{~km} / \mathrm{h}$ \\
\hline
\end{tabular}




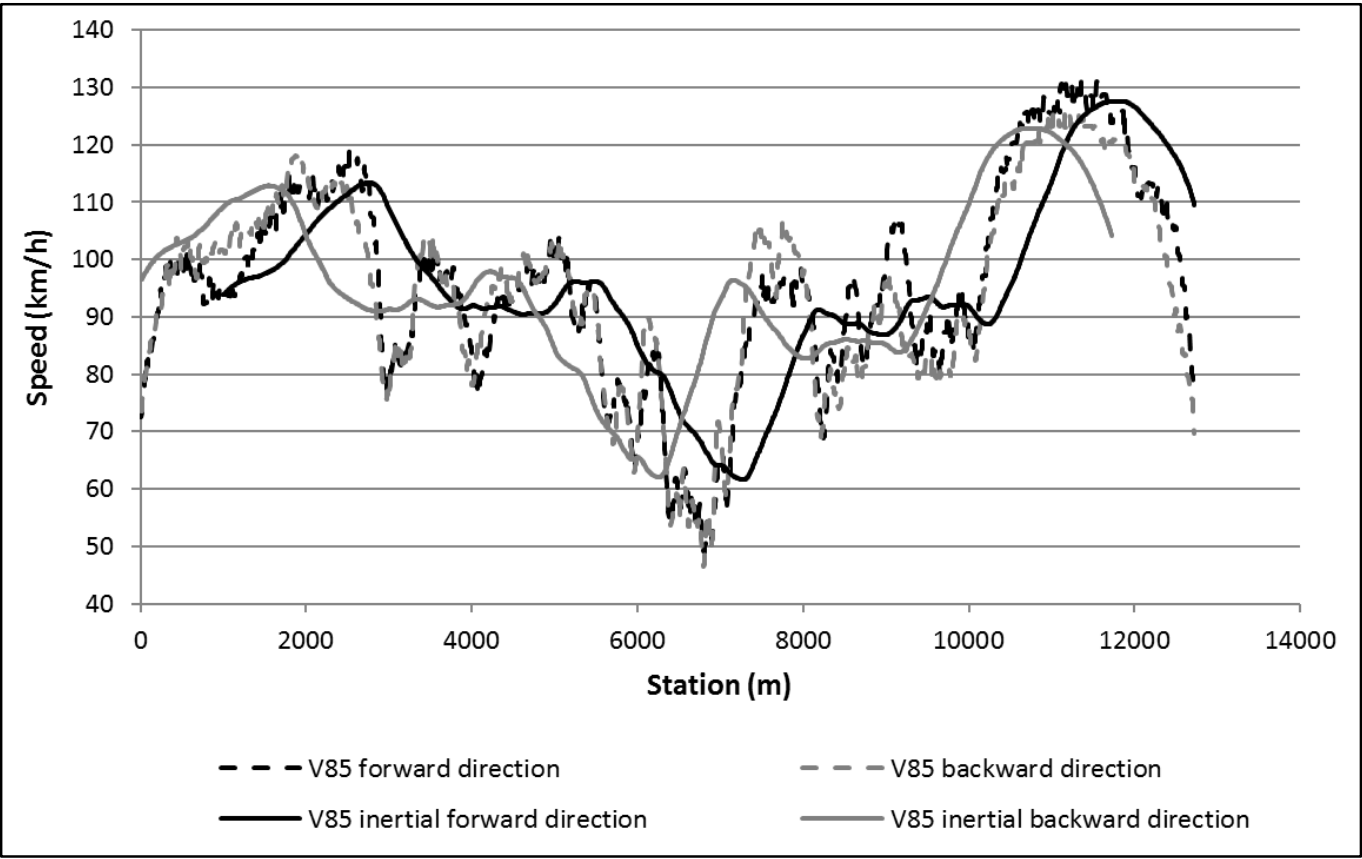

2 FIGURE 1 Example of inertial operating speed profile 


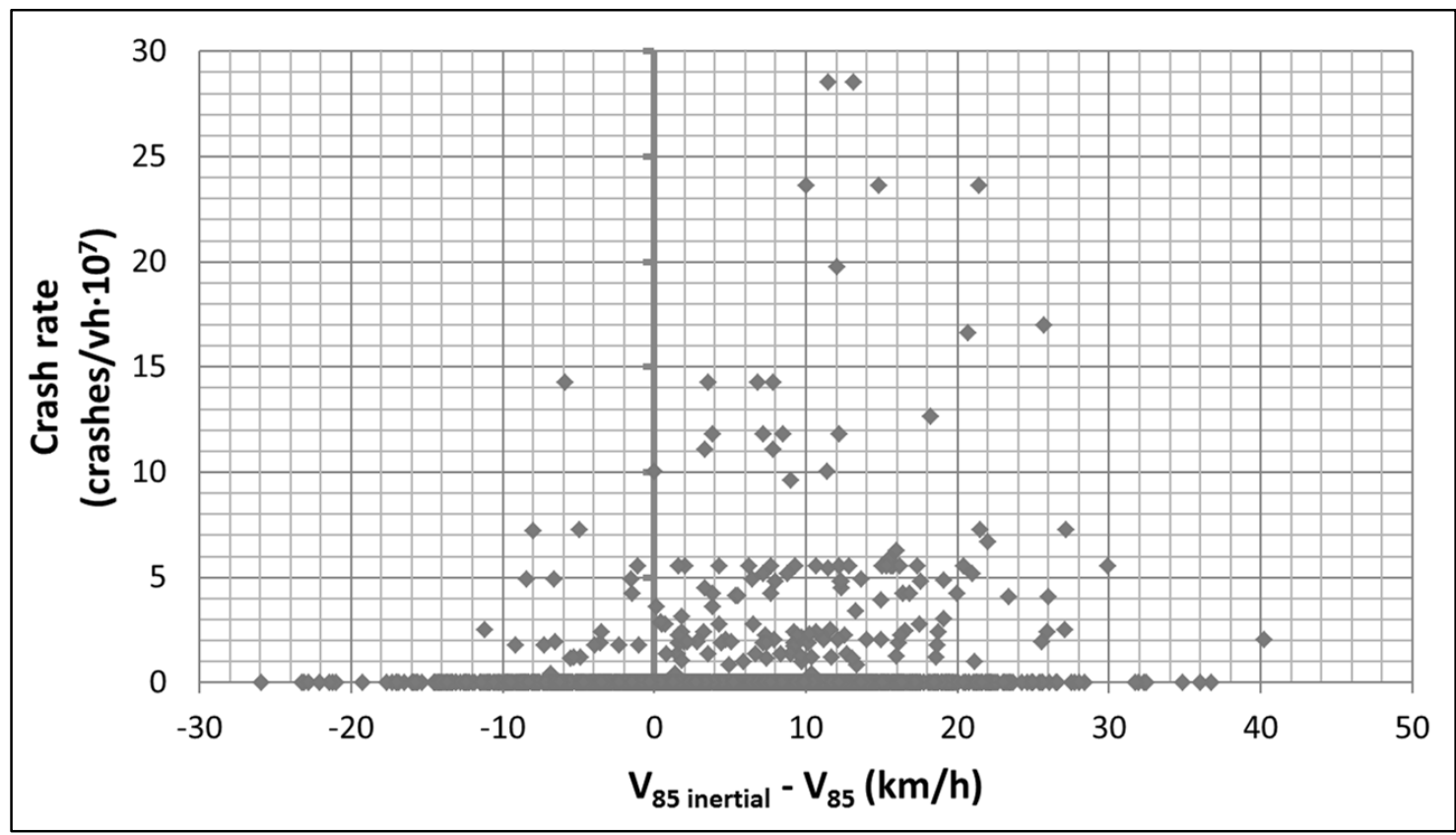

FIGURE 2 Crash rate vs ICI 


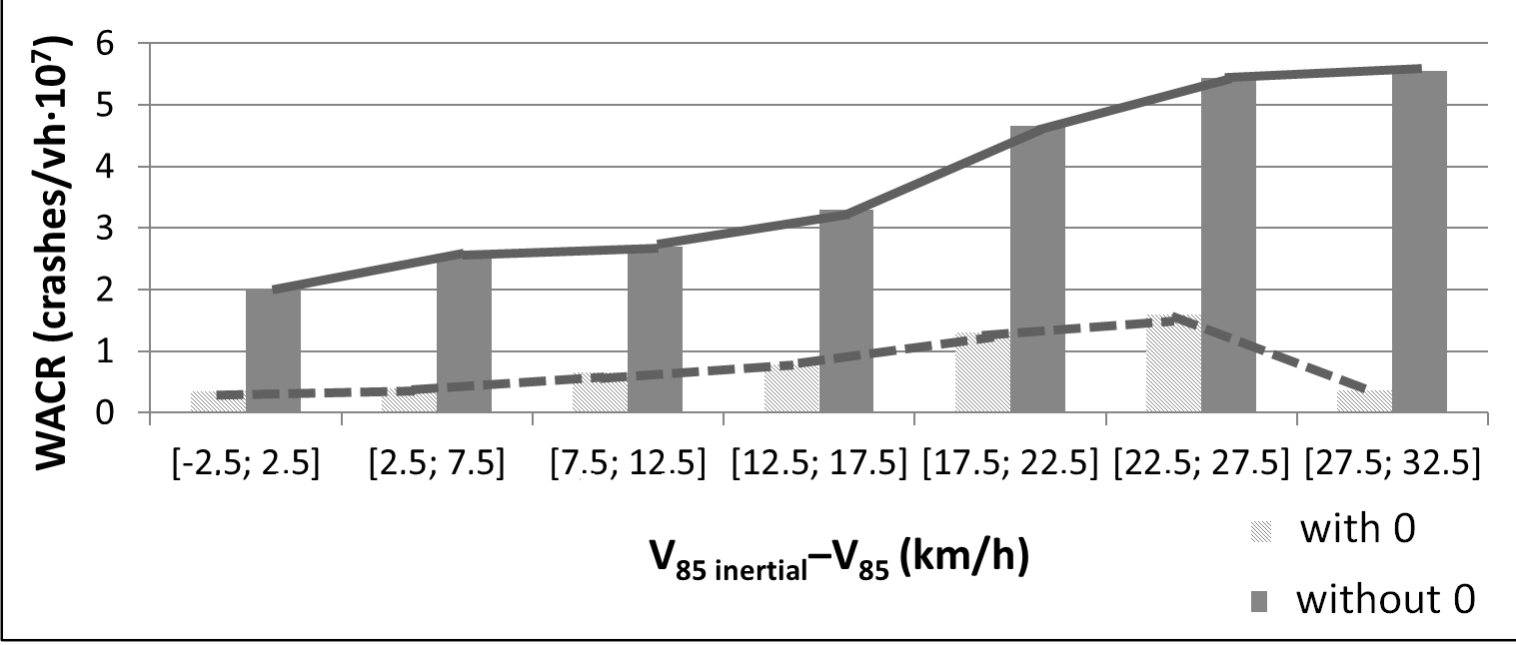

FIGURE 3 Weighted average crash rate vs ICI (5 km/h intervals) 


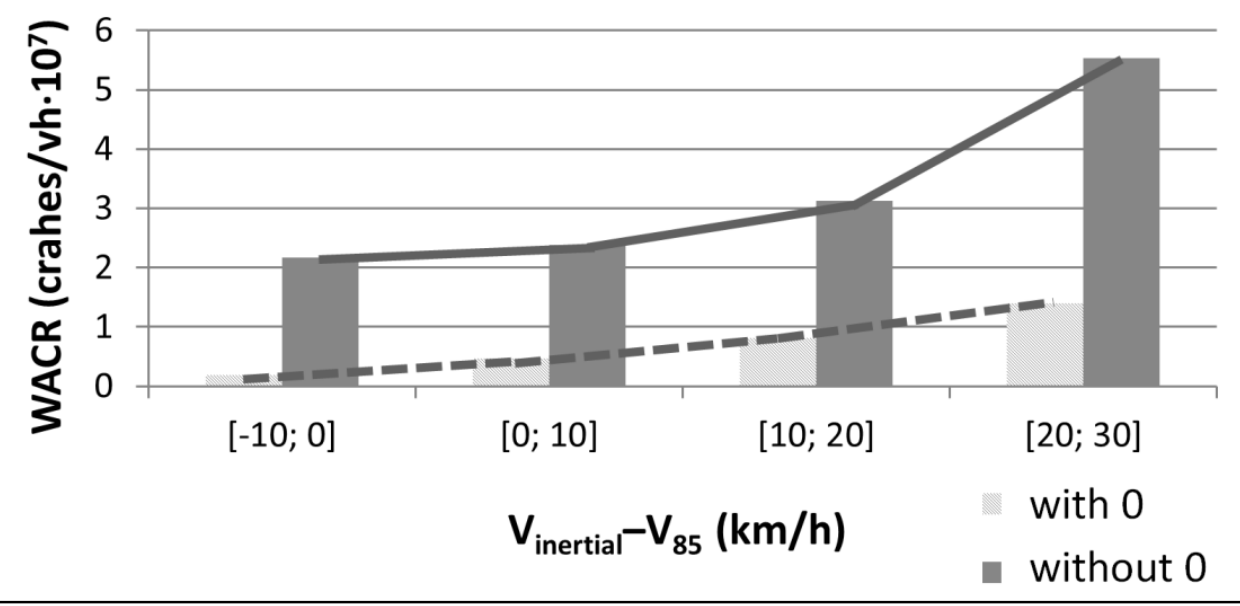




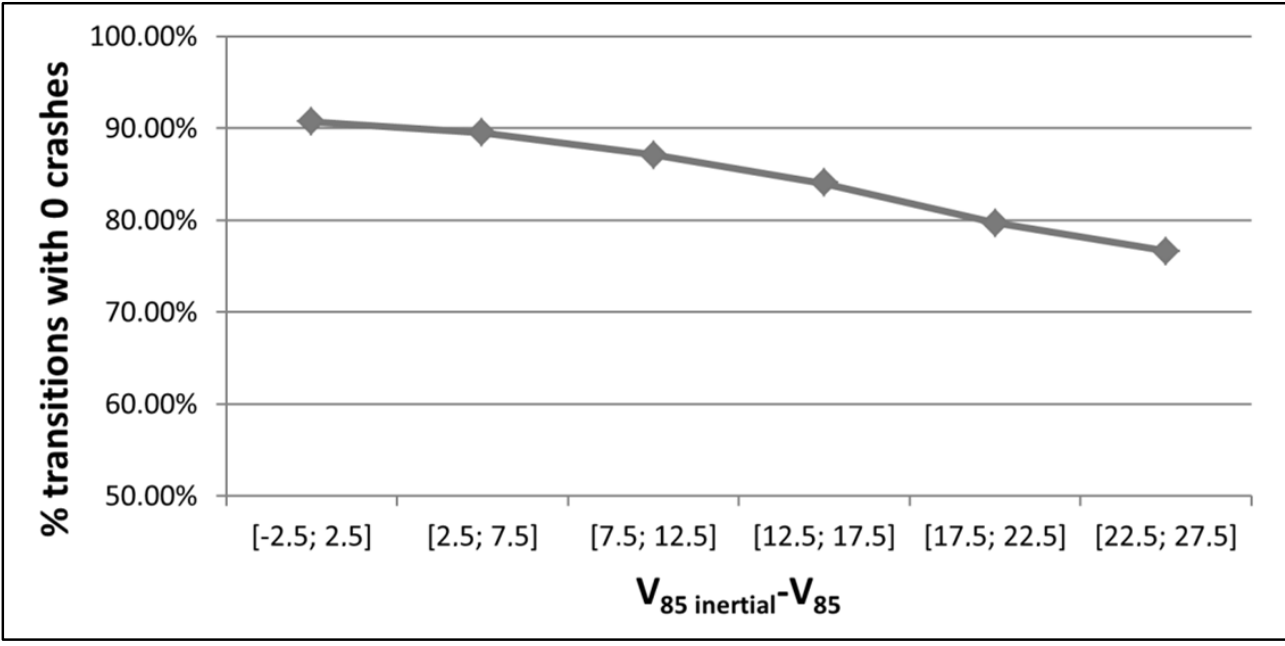

2 FIGURE 5 Percentage of blank transitions vs ICI ( $5 \mathrm{~km} / \mathrm{h}$ intervals) 


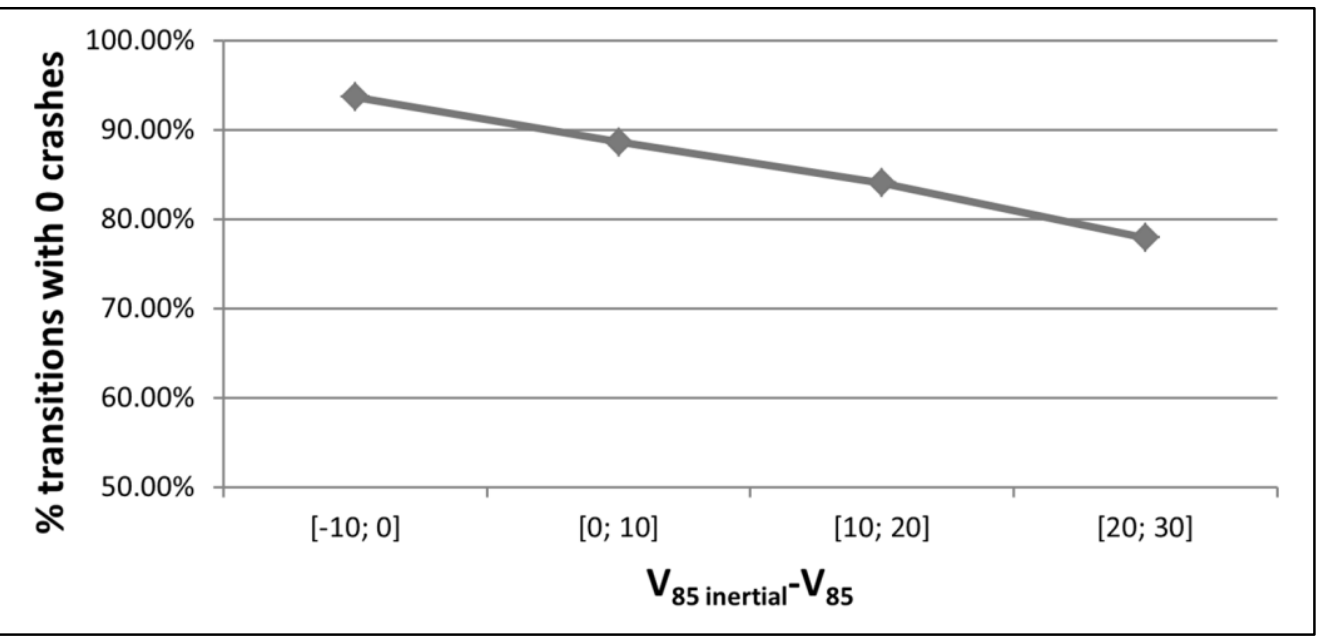

2 FIGURE 6 Percentage of blank transitions vs ICI $(10 \mathrm{~km} / \mathrm{h}$ intervals $)$ 


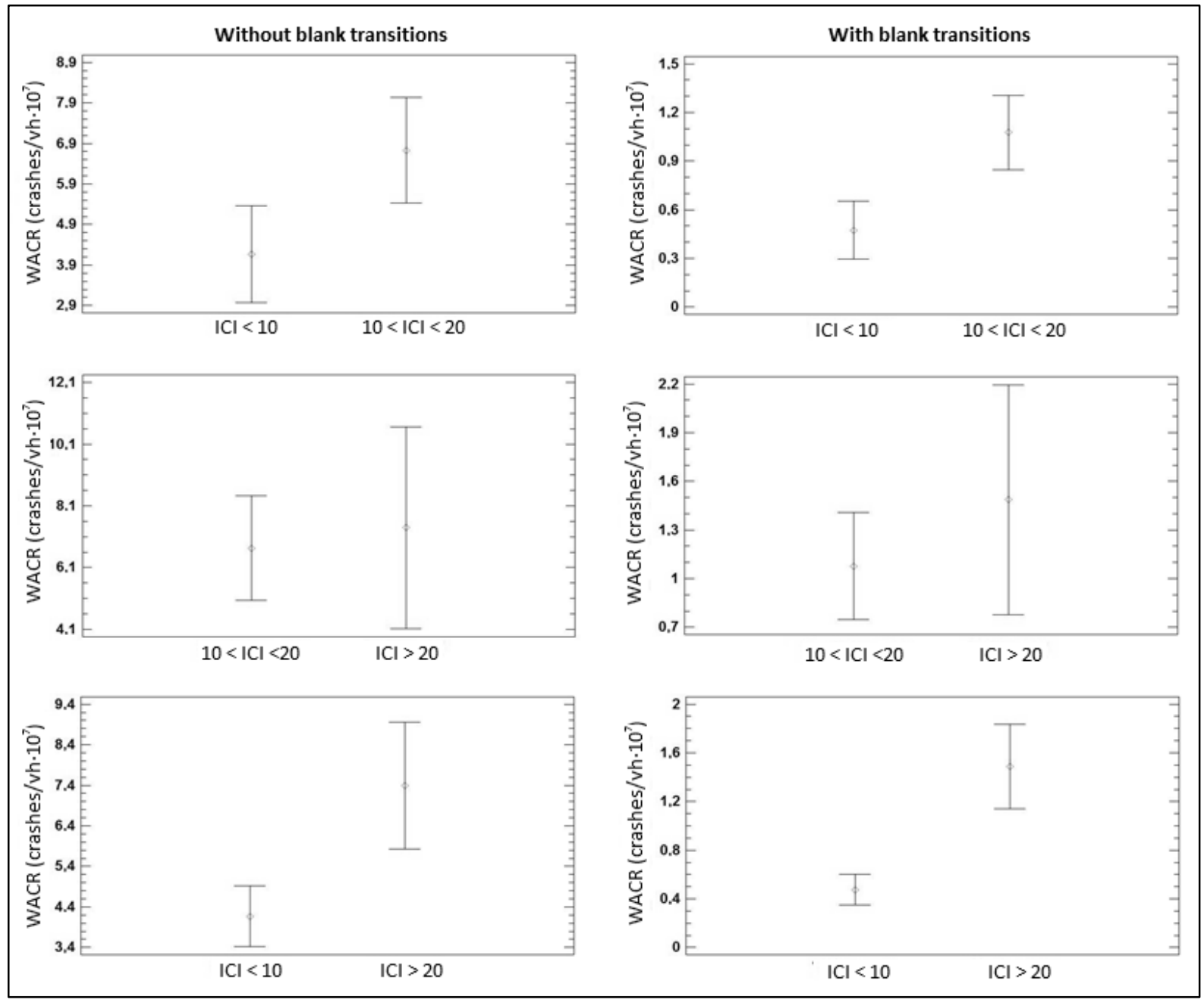

FIGURE 7 LSD intervals (95.0 percentage) for model thresholds determination 


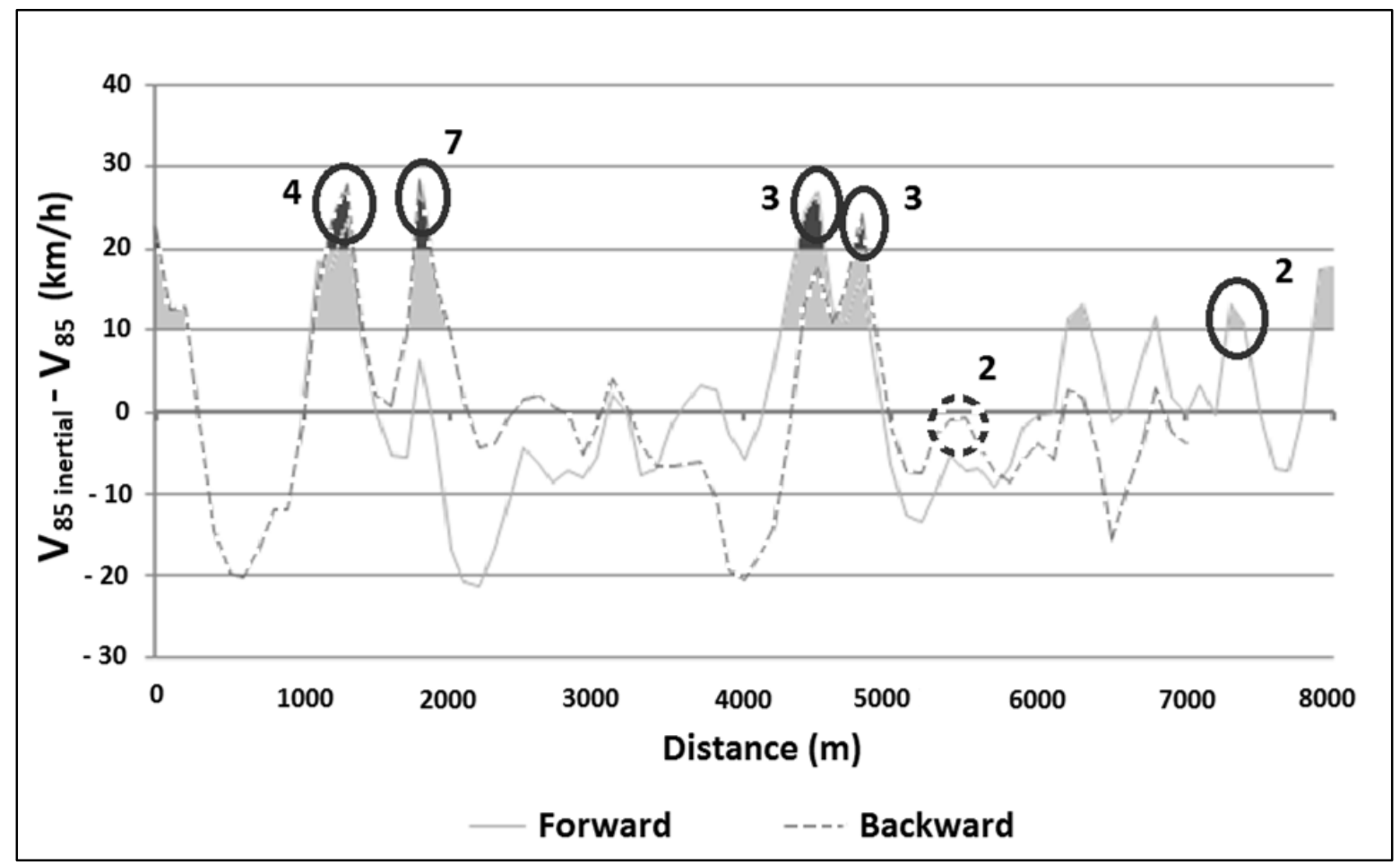

2 FIGURE 8 Validation road segment example. Inconsistencies identification and crashes location 3 


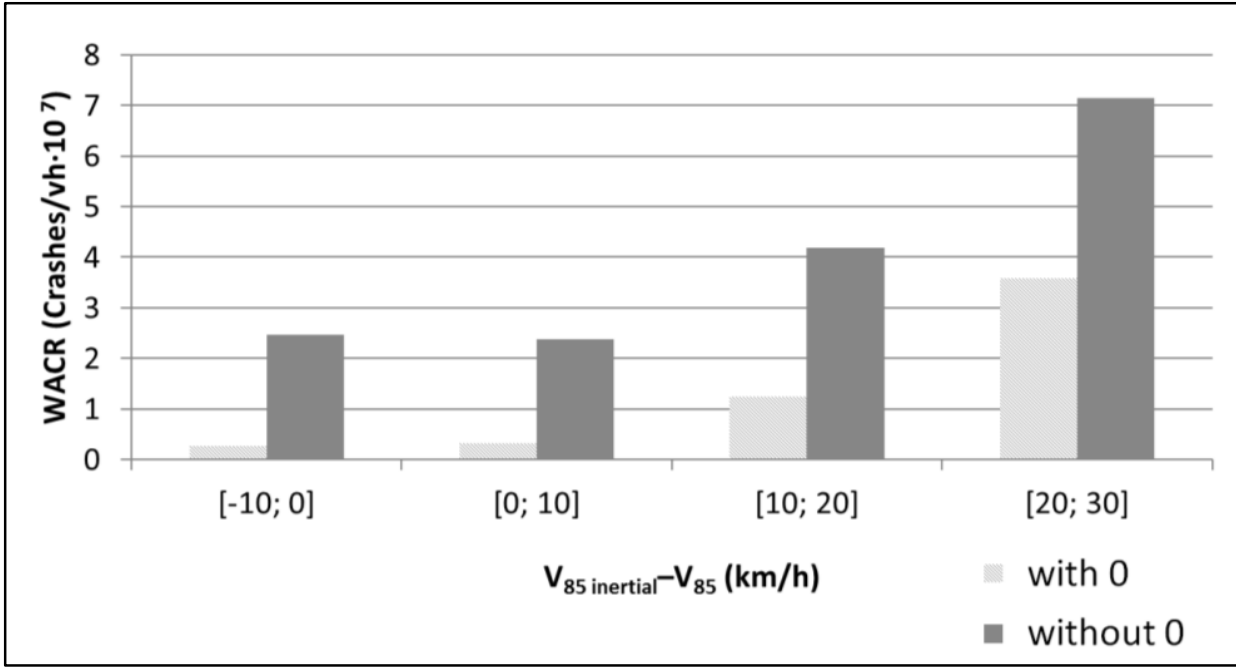

2

FIGURE 9 Weighted average crash rate vs ICI $(10 \mathrm{~km} / \mathrm{h}$ intervals) for validation road segments 3 